\title{
A pharmacoeconomic study of traditional anticoagulation versus direct oral anticoagulation for the treatment of venous thromboembolism in the emergency department
}

\author{
Stephanie Law, BSc(Pharm)*; Daljit Ghag, BSc(Pharm), Pharm D*; Eric Grafstein, MD ${ }^{\dagger \neq}$; Robert \\ Stenstrom, MD, $\mathrm{PhD}^{\dagger \neq}$; Devin Harris, MD, $\mathrm{MHSc}^{\ddagger \S}$
}

\section{ABSTRACT}

Objectives: Patients with venous thromboembolism (VTE) (deep vein thrombosis [DVT] and pulmonary embolism [PE]) are commonly treated as outpatients. Traditionally, patients are anticoagulated with low-molecular-weight heparin (LMWH) and warfarin, resulting in return visits to the ED. The direct oral anticoagulant (DOAC) medications do not require therapeutic monitoring or repeat visits; however, they are more expensive. This study compared health costs, from the hospital and patient perspectives, between traditional versus DOAC therapy.

Methods: A chart review of VTE cases at two tertiary, urban hospitals from January 1, 2010 to December 31, 2012 was performed to capture historical practice in VTE management, using $\mathrm{LMWH} /$ warfarin. This historical data were compared against data derived from clinical trials, where a DOAC was used. Cost minimization analyses comparing the two modes of anticoagulation were completed from hospital and patient perspectives.

Results: Of the 207 cases in the cohort, only 130 (63.2\%) were therapeutically anticoagulated (international normalized ratio 2.0-3.0) at emergency department (ED) discharge; patients returned for a mean of 7.18 (range: 1-21) visits. Twenty-one $(10 \%)$ were admitted to the hospital; $4(1.9 \%)$ were related to VTE or anticoagulation complications. From a hospital perspective, a DOAC (in this case, rivaroxaban) had a total cost avoidance of $\$ 1,488.04$ per VTE event, per patient. From a patient perspective, it would cost an additional $\$ 204.10$ to $\$ 349.04$ over 6 months, assuming no reimbursement.

Conclusions: VTE management in the ED has opportunities for improvement. A DOAC is a viable and cost-effective strategy for VTE treatment from a hospital perspective and, depending on patient characteristics and values, may also be an appropriate and cost-effective option from a patient perspective.
RÉSUMÉ

Objectif: Les patients souffrant d'une thromboembolie veineuse (TEV) (thrombose veineuse profonde [TVP] ou embolie pulmonaire [EP]) sont souvent traités en consultation externe. L'anticoagulation se réalise habituellement par I'héparine de faible masse moléculaire (HFMM) et par la warfarine, ce qui nécessite des consultations ultérieures au service des urgences (SU). II existe aussi I'anticoagulation orale directe (AOD), qui ne nécessite pas de surveillance thérapeutique ou de consultations rapprochées, mais son coût est plus élevé que celui du traitement classique. L'étude décrite ici visait donc à comparer les coûts, liés aux soins de santé, de l'anticoagulation classique avec ceux de I'AOD, et ce, tant pour les hôpitaux que pour les patients.

Méthode: Les auteurs ont procédé à un examen des dossiers des cas de TEV traités dans deux hôpitaux urbains, de soins tertiaires, pour la période du $1^{\mathrm{er}}$ janvier 2010 au 31 décembre 2012, afin de recueillir des données sur la pratique historique du traitement de la TEV par I'HFMM et la warfarine. II y a eu par la suite comparaison des données historiques avec celles provenant d'essais cliniques d'anticoagulants oraux directs. Enfin, des analyses de minimisation des coûts ont été effectuées afin que soient comparés les coûts des deux modalités de traitement anticoagulant, et ce, tant pour les hôpitaux que pour les patients.

Résultats: La cohorte comptait 207 cas et, dans seulement $130(63,2 \%)$ d'entre eux, le degré d'anticoagulation était suffisant sur le plan thérapeutique (RIN : 2,0-3,0) au moment du congé du SU; le suivi des patients a nécessité en moyenne 7,18 (plage : 1-21) consultations. Vingt et un (10\%) patients ont été hospitalisés, dont $4(1,9 \%)$ pour des complications liées à la TEV ou à l'anticoagulation. Du point de vue des hôpitaux, I'AOD (en l'occurrence, le rivaroxaban) a permis d'éviter des coûts totaux de 1488,04 \$ par TEV, par patient. Du

From the *Department of Pharmacy, Vancouver General Hospital, Vancouver, BC; †Department of Emergency Medicine, St. Paul's Hospital, Vancouver, BC; ¥Department of Emergency Medicine, University of British Columbia, Vancouver, BC; and §Department of Emergency Medicine, Kelowna General Hospital, Kelowna, BC.

Correspondence to: Dr. Devin Harris, Department of Emergency Medicine, Kelowna General Hospital, 2268 Pandosy Avenue, Kelowna, BC V1Y 1T2; Email: devinh@shaw.ca 
point de vue des patients, le traitement entraînerait des coûts additionnels variant de 204,10 \$ à 349,04 \$ sur une période de six mois, en cas de non-remboursement.

Conclusions: II y a place à l'amélioration dans la prise en charge de la TEV au SU. L'AOD se montre une stratégie durable et rentable du traitement de la TEV pour les hôpitaux; elle peut aussi se révéler une modalité appropriée et rentable pour les patients, selon les caractéristiques et les valeurs de chacun.

Keywords: venous thromboembolism, anticoagulants, costs and cost analysis, emergency medicine

\section{INTRODUCTION}

Venous thromboembolism (VTE) (deep vein thrombosis [DVT] and pulmonary embolism [PE]) is commonly diagnosed and treated in the emergency department (ED). The annual incidence of first time VTE events in the general population (excluding hospitalized patients) is approximately 1 per $1000 .{ }^{1}$ An increasing proportion of patients with a diagnosis of low-risk $\mathrm{PE}$ is now also being managed predominantly as outpatients. Traditionally, patients are anticoagulated through the administration of low-molecular-weight heparin ( $\mathrm{LMWH}$ ) as a bridging agent and vitamin $\mathrm{K}$ antagonists such as warfarin. ${ }^{2-4}$ However, full anticoagulation is not achieved immediately with warfarin, and there is great inter-patient variability in dosage requirements due to genetic polymorphisms. ${ }^{1-6}$ For these reasons, it often takes a minimum of 5 days for patients to reach two consecutive therapeutic international normalized ratios (INRs) of between 2.0 and 3.0, requiring daily $\mathrm{ED}$ visits in some settings. ${ }^{1-6}$ In two large multicentre clinical trials comparing a direct oral anticoagulant (DOAC) to traditional therapy, the median duration of LMWH (enoxaparin) treatment while bridging to a vitamin $\mathrm{K}$ antagonist was 8 days (interquartile range 6 to 11 days). ${ }^{7,8}$ After discharge from the ED, warfarin therapy poses additional challenges to the patient such as continued laboratory monitoring, compliance, and drug interactions. ${ }^{1,3-5}$

From a hospital perspective, each ED visit is costly, in terms of personnel and resources. Additionally, from a patient perspective, the ED visits are inconvenient and time-consuming; each visit can consume up to 3 to 4 hours of time, often for a minimum of 5 days.

There is substantial evidence from randomized clinical trials, meta-analyses, and clinical practice guidelines supporting the use of DOACs, also called novel oral anticoagulants (NOACs), in the treatment of VTE. ${ }^{2,3,7-9}$ Rivaroxaban (Xarelto), a factor Xa inhibitor, was the first DOAC approved for VTE treatment in Canada, based on EINSTEIN-DVT, which showed non-inferiority of rivaroxaban to standard therapy. ${ }^{7}$ Because it does not require therapeutic monitoring (i.e., daily INR testing) and its therapeutic effect is immediate, patients diagnosed with VTE can be treated with rivaroxaban in the outpatient setting without the need to return to the ED daily. ${ }^{1,5}$ However, rivaroxaban, as with other DOACs, is more expensive than warfarin, is not yet on many hospital formularies in Canada for VTE treatment, and has limited coverage by third-party payers.

This study was designed in order to evaluate the historical standard of VTE management in two large Canadian EDs and to compare the costs between traditional and rivaroxaban anticoagulation in this population. It was hypothesized that the administration of a DOAC for VTE in the ED would be less expensive than traditional anticoagulation with warfarin and $\mathrm{LMWH}$, from a hospital perspective.

\section{METHODS}

The study consisted of two parts. The first part was a chart review to determine historical outcomes of VTE management where LMWH/warfarin were used. The second part modeled these historical outcomes against VTE outcomes derived from published DOAC clinical trials. A cost minimization analysis was then performed comparing these two modes of anticoagulation, both from a hospital and a patient perspective, in Canadian dollars.

The protocol for the study was approved by University of British Columbia, Providence Health Care Research Ethics Board (UBC-PHC REB \#H13-01730), and Fraser Health Research Ethics Board (FHREB \#2013-078).

\section{Chart review}

In the first part, cases for review were identified via the Providence Health Emergency Department Discharge Database using keywords of "DVT," "PE," and "VTE" in the Presenting Complaint Description, National Ambulatory Care Reporting System Description, 
Diagnosis Name from January 1, 2010 to December 31, 2012. This included data from a large academic inner city hospital with an ED census of 78,000 visits, and an acute care community hospital with a census of 25,000 visits, in Vancouver, British Columbia.

Patients were included if they presented for a minimum of one ED visit with a diagnosis of VTE. For the purposes of this study, all subsequent visits within 30 days of eligibility and discharges (therapeutic INR for 2 consecutive days) were included as it was viewed that it was a resource burden to the ED. Patients with two separate diagnoses of VTE greater than 30 days after two therapeutic INRs had been obtained were quantified as two separate events. During the initial screening, patients without radiological findings consistent with VTE diagnosis and/or documentation of a negative d-dimer (less than $500 \mathrm{mcg} / \mathrm{L}$ ) were excluded. In addition, patients who did not undergo radiological investigations in the ED were excluded because a diagnosis of VTE could not be confirmed. Those who presented with isolated superficial thrombophlebitis or were misclassified in the discharge database were also excluded. Other exclusion criteria were admission to hospital, lack of British Columbia personal health number, treatment with a DOAC, ongoing monotherapy with warfarin or $\mathrm{LMWH}$, inferior vena cava filter in situ prior to VTE diagnosis, and patients who left against medical advice prior to emergency staff assessment (Figure 1). High-risk populations where DOACs are not recommended were also excluded, such as active cancer (currently undergoing chemotherapy, radiotherapy, or surgery), pregnancy, and renal dysfunction (estimated glomerular filtration rate [eGFR] less than $30 \mathrm{~mL} / \mathrm{min}$ ). Last, patients who did not have an updated eGFR within 6 months of diagnosis were also excluded.

Demographic data and measures of health care utilization were collected during the chart review. Diagnosis and location of DVT or PE, gender, age, risk factors for VTE (i.e., recent surgery/trauma, immobilization, recent flight, thrombophilic disorder) were extracted from patient electronic charts. In addition, the total number of ED visits, length of stay per visit, number and type of laboratory tests per visit (excluding ultrasounds and computerized tomography scans), and types of medication received were recorded. Length of ED visits were rounded off to the nearest hour, with a minimum of 1 hour. INR, hemoglobin, and eGFR were also collected if performed during ED visit(s). Patient outcomes (death or unscheduled readmissions within 7 months of index visit) were determined from linkage to the Vancouver Coastal Health Regional Emergency Department database. Application Secure Access software was used to access outpatient lab information to follow up and assess for changes in hemoglobin and INR values.

The electronic chart review and data collection were completed in adherence with standardized chart review methodology. ${ }^{10}$ Two reviewers (SL and $\mathrm{KH}$ ) were trained in chart abstraction and performed the chart reviews. The research team met regularly during the study to resolve any discrepancies identified during patient screening and data collection in order to maintain consistency and standardization. Data were cumulatively collected using a standardized Microsoft Excel spreadsheet. One of the investigators (DH) performed a review of a random sample of 20 of the VTE cases to determine reliability. The $\kappa$-statistic was used to measure inter-rater agreement.

\section{Cost minimization analyses}

Therapy with rivaroxaban has been shown to be non-inferior and comparable to standard therapy with LMWH/warfarin for VTE treatment. ${ }^{7,8}$ In other words, both VTE outcomes (re-occurrence, death) and bleeding (major and minor) have been found to be non-inferior to LMWH/warfarin. Therefore, a cost minimization analyses was completed from both hospital and patient perspectives, using direct costs. Health care utilization costs were determined from Canadian Institute of Health Information (CIHI) ${ }^{11}$ Centre for Health Services and Policy Research (CHSPR), British Columbia Ministry of Health, ${ }^{12}$ and Lower Mainland Pharmacy Services (LMPS) where applicable.

\section{Hospital cost perspective}

Direct fixed and variable costs for first and subsequent ED visits were taken into account. This included personnel (admitting clerk, registered nurse, physician, phlebotomist, etc.), supplies (syringes, needles, cups, etc.), laboratory tests, and medications. For traditional anticoagulation, cost analysis was based on the mean number of ED visits identified from the historical cohort. For rivaroxaban, it was assumed that patients would visit the ED only once for diagnosis and appropriate treatment and would not return for subsequent visits.

\section{Patient cost perspective}

Direct costs endured during emergency visits and after discharge were taken into account for the patient 


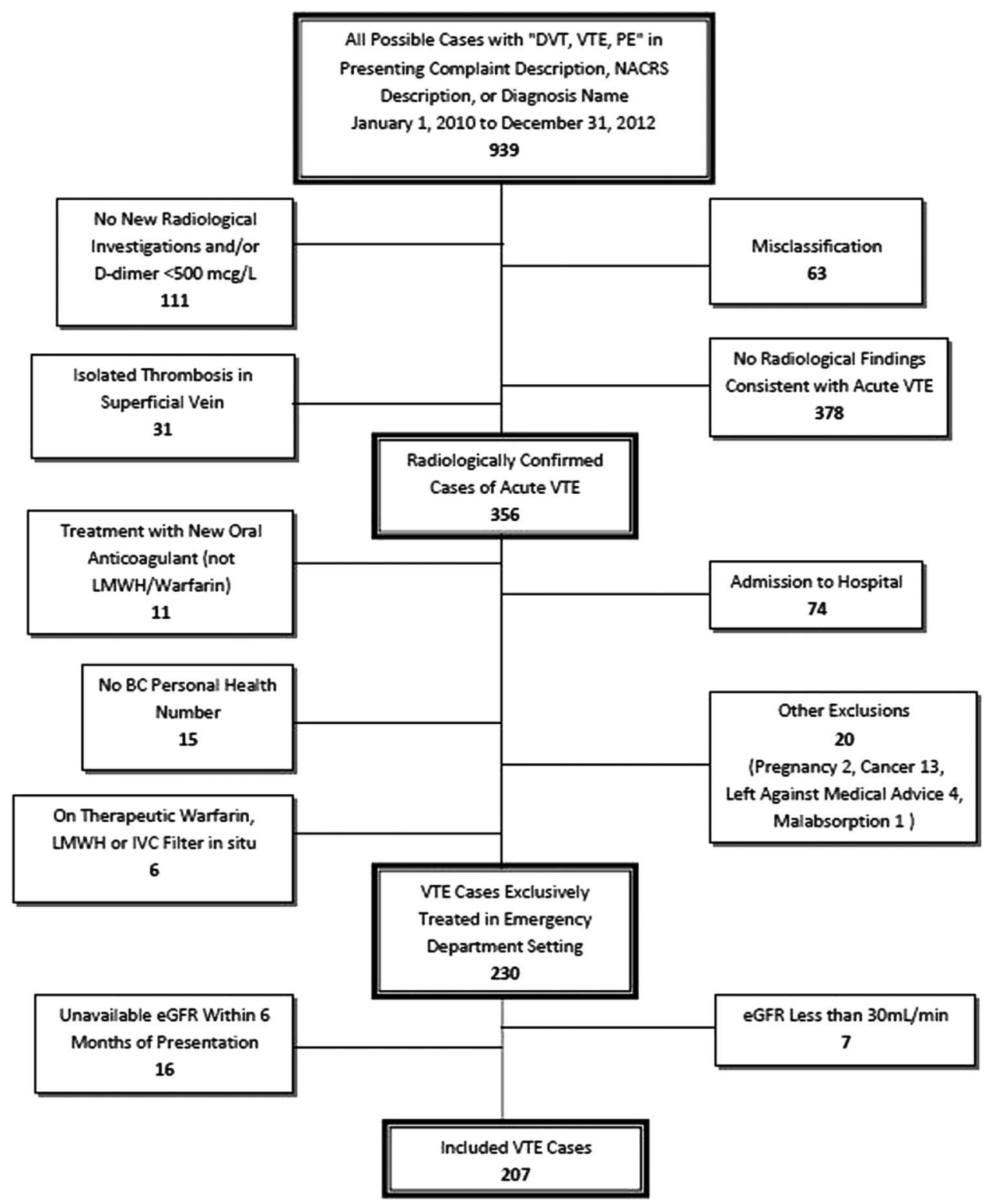

Figure 1. Case inclusion flow chart. Number of VTE cases identified via emergency discharge database and, after screening and exclusions, were included in the historical cohort.

perspective cost analysis. This included parking, mileage, time off work, cost of medications, and dispensing fees. It was conservatively assumed that a patient had a minimum wage occupation ( $\$ 10.25$ in BC) and had no extended health coverage. This analysis assumed a 6-month treatment duration. Parking fees and mileage from the hospital, lab, and physician office were estimated via BC Ministry of Finance mileage entitlement and current guidelines for monitoring of warfarin therapy. ${ }^{13}$ The duration of ED visits, which is the expected time away from work, was obtained via the chart review. It was assumed that the patient had biweekly INRs until four consecutive therapeutic INRs, and then monthly INRs and biweekly family physician visits for the first 2 months then phone reviews if on warfarin. Two family physician visits were assumed if the patient was on DOAC therapy.

\section{Outcomes}

The primary outcome was the cost difference between standard and DOAC therapy for VTE treatment in the $\mathrm{ED}$, from a hospital perspective. A patient perspective cost analysis was conducted to address potential 
concerns that the direct patient costs would be a barrier to DOAC therapy. Secondary outcomes included the rate of therapeutic anticoagulation at ED discharge, mean number of ED visits, all-cause mortality, all-cause readmission to hospital, and major bleeding, defined as a hemoglobin drop greater than $20 \mathrm{~g} / \mathrm{L}$. Clinical outcomes were followed over 6 months from time of diagnosis with an additional 30-day follow-up after discontinuation of therapy. Duration of anticoagulation varies with location and cause (provoked or unprovoked) of VTE,

\begin{tabular}{|c|c|c|c|}
\hline & $\begin{array}{l}\text { Historical } \\
\text { cohort } \\
(n=207)\end{array}$ & $\begin{array}{c}\text { Rivaroxaban } \\
\text { therapy } \\
\text { (EINSTEIN) } \\
(n=4150)^{14}\end{array}$ & $\begin{array}{c}\text { Standard } \\
\text { therapy } \\
(\text { EINSTEIN) } \\
(\mathrm{n}=4131)^{14}\end{array}$ \\
\hline Age (years \pm SD) & $56.3 \pm 17.6$ & $57.0 \pm 17.0$ & $57.0 \pm 16.8$ \\
\hline $\begin{array}{l}\text { Male sex, \% } \\
\text { Risk factor associated } \\
\text { with VTE - \% }\end{array}$ & 63.3 & 55.5 & 56.3 \\
\hline Previous VTE & 31.9 & 19.1 & 19.8 \\
\hline $\begin{array}{l}\text { Known thrombophilic } \\
\text { condition }\end{array}$ & 5.8 & 5.9 & 5.7 \\
\hline Recent surgery/trauma & 22.7 & 18.1 & 17.7 \\
\hline Immobilization & 15.4 & 15.6 & 15.5 \\
\hline Estrogen therapy & 2.9 & 8.4 & 8.2 \\
\hline History of cancer & 1.9 & 5.6 & 4.8 \\
\hline Unprovoked & 57.0 & 63.1 & 63.8 \\
\hline
\end{tabular}

Table 2. VTE diagnosis in historical cohort

\begin{tabular}{lc} 
Diagnosis, $n(\%)$ & Historical cohort $(n=207)$ \\
\hline Deep vein thrombosis (DVT) & $173(83.6)$ \\
Pulmonary embolism (PE) & $12(5.8)$ \\
DVT \& superficial & $16(7.7)$ \\
DVT \& PE & $5(2.4)$ \\
DVT, PE, \& superficial & $1(0.5)$
\end{tabular}

and 6 months of anticoagulation were deemed appropriate for this study among the study investigators after consultation with hematologists and internists at the outpatient anticoagulation clinic.

\section{RESULTS}

\section{Chart review}

A total of 939 patient encounters were screened and after exclusions, 207 VTE cases were included (see Figure 1). Cohen's kappa for inclusion in the study was found to be 0.83 (95\% confidence interval = 0.78-0.88). Baseline characteristics are shown in Table 1. The mean age was $56.3 \pm 17.6 \mathrm{yr}$, and 131 (63.3\%) were men; $173(83.6 \%)$ of the VTE cases were DVT, 12 (5.8\%) were PE, and the remaining were a combination of both with or without superficial thrombophlebitis (Table 2); 130 (63.2\%) VTE cases were discharged from the ED appropriately after achieving therapeutic anticoagulation, (INR 2.0-3.0) returning to the $\mathrm{ED}$ for a mean of 7.18 visits (range 1-21). The mean duration of visits was 1.65 hours (range 1-17). A total of 21 patients (10\%) were readmitted to hospital, with $4(1.9 \%)$ rehospitalizations related to VTE or anticoagulation complications. Major bleeding occurred in $8(3.9 \%)$ patients, and 5 (2.4\%) patients died during the predefined follow-up period of 7 months after diagnosis (Table 3 ).

\section{Cost minimization analyses}

\section{Hospital perspective}

When traditional (warfarin/LMWH) and rivaroxaban anticoagulation were compared for the treatment of VTE in the ED, rivaroxaban was associated with a cost avoidance of $\$ 1,488.04$ per VTE event. This was inclusive of costs incurred by the hospital during initial and subsequent visits (Table 4).

\section{Table 3. Clinical outcomes compared with EINSTEIN trials}

\begin{tabular}{|c|c|c|c|c|c|}
\hline & $\begin{array}{l}\text { Historical Cohort } \\
\qquad(n=207)\end{array}$ & $\begin{array}{c}\text { Rivaroxaban } \\
\text { EINSTEIN DVT } \\
(n=1718)^{7}\end{array}$ & $\begin{array}{c}\text { Standard } \\
\text { EINSTEIN DVT } \\
(n=1711)^{7}\end{array}$ & $\begin{array}{c}\text { Rivaroxaban } \\
\text { EINSTEIN PE } \\
(n=2412)^{8}\end{array}$ & $\begin{array}{c}\text { Standard } \\
\text { EINSTEIN PE } \\
(n=2405)^{8}\end{array}$ \\
\hline Readmissions, $\mathrm{n}(\%)$ & $21(10)$ & - & - & - & - \\
\hline Related to VTE/ anticoagulation complications & $4(1.9)$ & - & - & - & - \\
\hline All-cause mortality, n (\%) & $5(2.4)$ & $38(2.2)$ & $49(2.9)$ & $58(2.4)$ & $50(2.1)$ \\
\hline Major bleeding, n (\%) & $8(3.9)$ & $14(0.8)$ & $20(1.2)$ & $26(1.1)$ & $52(2.2)$ \\
\hline
\end{tabular}


Traditional versus direct oral anticoagulant treatment of VTE in the ED

\begin{tabular}{|c|c|c|c|c|c|c|}
\hline \multirow[b]{2}{*}{ Emergency department - first visit } & \multicolumn{3}{|c|}{ Traditional anticoagulation warfarin/LMWH } & \multicolumn{3}{|c|}{ Direct oral anticoagulation rivaroxaban } \\
\hline & Unit cost (p) & Quantity (q) & Total $(p \times q)$ & Unit cost (p) & Quantity (q) & Total $(p \times q)$ \\
\hline Fixed costs per visit (personnel, supplies, etc.) & $\$ 166.00$ & 1 & $\$ 166.00$ & $\$ 166.00$ & 1 & $\$ 166.00$ \\
\hline \multicolumn{7}{|l|}{ Variable costs per visit } \\
\hline Laboratory: CBC, renal & $\$ 15.25$ & 1 & $\$ 15.25$ & $\$ 15.25$ & 1 & $\$ 15.25$ \\
\hline Laboratory: INR & $\$ 10.68$ & 1 & $\$ 10.68$ & $\$ 10.68$ & 1 & $\$ 10.68$ \\
\hline Medication: dalteparin & $\$ 55.56$ & 1 & $\$ 55.56$ & $\$ 55.56$ & 0 & $\$ 0.00$ \\
\hline Medication: warfarin & $\$ 0.01$ & 1 & $\$ 0.01$ & $\$ 0.01$ & 0 & $\$ 0.00$ \\
\hline Medication: rivaroxaban & $\$ 2.84$ & 0 & $\$ 0.00$ & $\$ 2.84$ & 1 & $\$ 2.84$ \\
\hline Total first visit costs & & & $\$ 247.50$ & & & $\$ 194.77$ \\
\hline \multicolumn{7}{|l|}{ Emergency department - subsequent visit(s) } \\
\hline & \multicolumn{3}{|c|}{ Traditional anticoagulation warfarin/LMWH } & \multicolumn{3}{|c|}{ Direct oral anticoagulation rivaroxaban } \\
\hline & Unit cost (p) & Quantity (q) & Total $(p \times q)$ & Unit cost (p) & Quantity (q) & Total $(p \times q)$ \\
\hline Fixed costs per visit (personnel, supplies) & $\$ 166.00$ & 1 & $\$ 166.00$ & $\$ 166.00$ & 0 & $\$ 0.00$ \\
\hline \multicolumn{7}{|l|}{ Variable costs per visit } \\
\hline Laboratory: CBC, renal & $\$ 15.25$ & 0 & $\$ 0.00$ & $\$ 15.25$ & 0 & $\$ 0.00$ \\
\hline Laboratory: INR & $\$ 10.68$ & 1 & $\$ 10.68$ & $\$ 10.68$ & 0 & $\$ 0.00$ \\
\hline Medication: dalteparin & $\$ 55.56$ & 1 & $\$ 55.56$ & $\$ 55.56$ & 0 & $\$ 0.00$ \\
\hline Medication: warfarin & $\$ 0.01$ & 1 & $\$ 0.01$ & $\$ 0.01$ & 0 & $\$ 0.00$ \\
\hline Medication: rivaroxaban & $\$ 2.84$ & 0 & $\$ 0.00$ & $\$ 2.84$ & 0 & $\$ 0.00$ \\
\hline Total costs & & & $\$ 232.25$ & & & $\$ 0.00$ \\
\hline Mean number of subsequent visits & & & 6.18 & & & 0 \\
\hline Total subsequent visit costs & & & $\$ 1,435.31$ & & & $\$ 0.00$ \\
\hline $\begin{array}{l}\text { Cost minimization analysis } \\
=\text { Total costs (traditional) }- \text { total costs }(\mathrm{DOAC}) \\
=(\$ 247.50+\$ 1,435.31)-(\$ 194.77+\$ 0.00) \\
=+\$ 1,488.04 \mathrm{NTE} \text { event (in favour of DOAC) }\end{array}$ & & & & & & \\
\hline
\end{tabular}

\section{Patient perspective}

For a 6-month duration of therapy, the cost minimization analysis indicated that rivaroxaban would cost each patient an additional \$204.10 to \$349.04 (Tables 5 and 6). This was inclusive of costs during initial hospital ED visit(s) as well as outpatient therapy. Four visits to a family doctor for patients on traditional therapy were modeled on current guidelines for monitoring and therapy; ${ }^{2}$ two visits were estimated for those on rivaroxaban, that is, for represcribing and follow-up/counselling purposes.

\section{DISCUSSION}

In our historical VTE population treated with traditional anticoagulation, patient characteristics and clinical outcomes were similar to those seen in the control arms of the EINSTEIN trials (Tables 1 and 3). ${ }^{14}$ However, only $63.2 \%$ of our cohort was appropriately anticoagulated with warfarin upon completion of their multiday ED course of therapy. This anticoagulation rate is considerably lower than that found in EINSTEIN-DVT, and -PE $\left(80.8 \%, 83.2 \%\right.$ respectively) ${ }^{7,8}$ therefore, clinical trial results may be underestimating the benefit of rivaroxaban in a real world setting. The low therapeutic anticoagulation rate in our cohort could be attributed to that, in practice, practitioners may be more lenient regarding INRs-accepting bordering INR values of 1.9 to 3.1 , rather than 2.0 to 3.0 , as per clinical guidelines. ${ }^{2}$ Subtherapeutic anticoagulation might be avoided if rivaroxaban were used to manage this patient population. The VTE cases in the historical cohort returned to the ED for a mean of 7.18 visits, which is similar to what was seen in EINSTEIN-DVT (median 8 days). ${ }^{7}$

In the cost minimization analysis from the hospital perspective, rivaroxaban therapy was $\$ 1,488.04$ less costly than warfarin/LMWH. This assumes no return 
Table 5. Breakdown of costs: patient perspective

\begin{tabular}{|c|c|c|c|c|c|c|}
\hline & \multicolumn{3}{|c|}{ Traditional anticoagulation warfarin/LMWH } & \multicolumn{3}{|c|}{ Direct oral anticoagulation rivaroxaban } \\
\hline & Unit cost (p) & Quantity (q) & Total $(p \times q)$ & Unit cost (p) & Quantity (q) & Total $(p \times q)$ \\
\hline \multicolumn{7}{|l|}{ ED costs per visit } \\
\hline Drivers: Parking & $\$ 12.00$ & $1 \times 7.18$ visits & $\$ 86.16$ & $\$ 12.00$ & 1 & $\$ 12.00$ \\
\hline Drivers: Travel (mileage) $\$ 0.52 / \mathrm{km}$ & $\$ 0.52$ & $3 \mathrm{~km} \times 7.18$ visits & $\$ 11.20$ & $\$ 0.52$ & $3 \times 1$ visit & $\$ 1.56$ \\
\hline Time off work (min. wage) & $\$ 10.25$ & $1.65 \mathrm{~h} \times 7.18$ visits & $\$ 121.43$ & $\$ 10.25$ & $1.65 \mathrm{~h} \times 1$ visit & $\$ 16.91$ \\
\hline Total costs (driving) & & & $\$ 218.79$ & & & $\$ 30.47$ \\
\hline Total costs (walk-in) & & & $\$ 120.95$ & & & $\$ 16.91$ \\
\hline \multicolumn{7}{|l|}{ Outpatient costs } \\
\hline & \multicolumn{3}{|c|}{ Traditional anticoagulation warfarin/LMWH } & \multicolumn{3}{|c|}{ Direct oral anticoagulation rivaroxaban } \\
\hline & Unit cost (p) & Quantity (q) & Total $(p \times q)$ & Unit cost (p) & Quantity (q) & Total $(p \times q)$ \\
\hline Medication costs dispensing fee & $\$ 15.00$ & 2 & $\$ 30.00$ & $\$ 15.00$ & 2 & $\$ 30.00$ \\
\hline Warfarin 5-mg tabs & $\$ 0.08$ & 180 & $\$ 14.40$ & $\$ 0.08$ & 0 & $\$ 0.00$ \\
\hline Rivaroxaban $10 \mathrm{mg}$ & $\$ 1.73$ & 0 & $\$ 0.00$ & $\$ 1.73$ & 42 & $\$ 128.94$ \\
\hline Rivaroxaban 15 mg & $\$ 1.73$ & 0 & $\$ 0.00$ & $\$ 1.73$ & 147 & $\$ 451.29$ \\
\hline Direct patient costs - lab drivers: parking & $\$ 4.00$ & 9 & $\$ 36.00$ & $\$ 4.00$ & 0 & $\$ 0.00$ \\
\hline Drivers: travel mileage $(\$ 0.52 / \mathrm{km})$ & $\$ 0.52$ & $3 \mathrm{~km} \times 9$ visits & $\$ 14.04$ & $\$ 0.52$ & 0 & $\$ 0.00$ \\
\hline Time off work (min. wage) & $\$ 10.25$ & $1 \mathrm{~h} \times 9$ visits & $\$ 92.25$ & $\$ 10.25$ & 0 & $\$ 0.00$ \\
\hline \multicolumn{7}{|l|}{ Direct patient costs - family physician visits } \\
\hline Drivers: parking & $\$ 4.00$ & 4 & $\$ 16.00$ & $\$ 4.00$ & 2 & $\$ 8.00$ \\
\hline Drivers: travel mileage & $\$ 0.52$ & $3 \mathrm{~km} \times 4$ visits & $\$ 6.24$ & $\$ 0.52$ & $3 \mathrm{~km} \times 2$ visits & $\$ 3.12$ \\
\hline Time off work (min. wage) & $\$ 10.25$ & $1 \mathrm{~h} \times 4$ visits & $\$ 41.00$ & $\$ 10.25$ & $1 \mathrm{~h} \times 2$ visits & $\$ 20.50$ \\
\hline
\end{tabular}

\begin{tabular}{|c|c|c|c|}
\hline \multicolumn{4}{|c|}{ Traditional anticoagulation } \\
\hline & Emergency visits & Outpatient & Total \\
\hline Drivers & $\$ 218.29$ & $\$ 249.93$ & $\$ 468.22$ \\
\hline Walk-ins & $\$ 120.95$ & $\$ 177.65$ & $\$ 298.60$ \\
\hline \multicolumn{4}{|c|}{ Direct oral anticoagulation } \\
\hline Drivers & $\$ 30.47$ & $\$ 641.85$ & $\$ 672.32$ \\
\hline Walk-ins & $\$ 16.91$ & $\$ 630.73$ & $\$ 647.64$ \\
\hline \\
\hline \multicolumn{4}{|c|}{$=$ Total costs (traditional) - total costs $(\mathrm{DOAC})$} \\
\hline \multicolumn{4}{|c|}{ Drivers: $\$ 468.22-\$ 672.32=-\$ 204.10$} \\
\hline \multicolumn{4}{|c|}{$\begin{array}{l}\text { Walk-ins: } \$ 298.60-\$ 647.64=-\$ 349.04 \\
\text { DOAC= direct oral anticoagulant. }\end{array}$} \\
\hline
\end{tabular}

visits for those patients prescribed rivaroxaban, which may be over-optimistic. In a sensitivity analysis, patients prescribed rivaroxaban may return up to eight times to the ED (for reassessment, for example) and still show a cost savings versus traditional therapy. In those settings that have outpatient anticoagulation clinics (or in pharmacy settings), the cost difference would be considerably less because those practice settings are less costly than the ED. However, rivaroxaban therapy would still cost less than traditional therapy. Very minor differences in costs exist between rivaroxaban and the other DOACs (dabigatran [Pradaxa] and apixaban [Eliquis]); therefore, these cost savings would be similar if other DOACs were used in the analysis.

Along with the direct hospital costs that were accounted for in this study, there are several indirect hospital costs that were not quantified. The use of a DOAC would reduce the number of overall $\mathrm{ED}$ visits, possibly reduce ED crowding, hypothetically improve clinician availability to treat higher acuity patients, and possibly improve clinician and patient satisfaction.

It could be argued that the use of a DOAC may misallocate health care costs to the patient by reducing hospital ED visits. Passing the costs to patients is a significant issue; this may result in noncompliance and poor outcomes, including more downstream visits and complications. Therefore, the implications of using a DOAC over traditional anticoagulation for VTE treatment from a patient perspective were considered. Indeed, the cost minimization analysis showed an increased cost of approximately $\$ 200$ to $\$ 350$ to the 
patient over a 6-month treatment period. The additional cost was dependent on patient mode of transportation to the ED and outpatient appointments. This analysis was based on very conservative cost assumptions: that the patient is making minimum wage $(\$ 10.25 / \mathrm{hr})$ and does not have extended health coverage, including PharmaCare coverage. The transition point, in terms of patient wages, was found to be approximately $\$ 20.00 / \mathrm{hr}$. Wages at or beyond this hourly rate would reverse the cost analysis in favour of rivaroxaban therapy. Indirect costs of being on traditional therapy that could not be quantified included patient satisfaction (dietary and drug restrictions due to interaction risks, labile INRs, etc.), infectious risks secondary to multiple hospital visits, and caregiver time off work, if applicable. Additionally, the indirect value that a patient may put on his or her time is variable and may ultimately alter therapeutic decision-making. Although using rivaroxaban clearly uses less health care costs from a hospital perspective compared with traditional treatment, the selection between the two modes of anticoagulation should be evaluated on a caseby-case basis.

Finally, there are currently no approved antidotes for the DOACs in Canada. Although in development, the lack of approved antidotal therapy may impact both patients and providers in their decision-making.

\section{Limitations}

This study is limited in that it is a comparison of historical data from a chart review against data from clinical trials. Real-world data will inherently have worse outcomes than outcomes derived from a clinical trial. We tried to mitigate this bias by assuming conservative outcomes and bleeding risks, and performing sensitivity analyses, where possible. In this study, bleeding risk was assumed to be equivalent with traditional versus DOAC therapy; this finding has been confirmed in the literature. ${ }^{15}$ However, bleeding risk has not been firmly established with DOACs, in comparison to traditional anticoagulation, outside clinical trial settings. This may alter outcomes and, therefore, have cost implications that may alter the conclusions from this analysis.

In addition, this study is limited by the inherent biases of a chart review, including missing data and misclassification. Clinical outcomes such as rehospitalization and mortality may be incomplete if patient was out of the province or country. Rehospitalization data were not collected in EINSTEIN; therefore, a direct comparison could not be made. It is important to take note that both EINSTEIN trials included outpatients and inpatients, whereas our population consisted of outpatients only.

As with any economic analysis, there are limitations in the determination of outcomes and costs. This was a cost-minimization analysis; outcomes (both re-occurrence, mortality, and bleeding) were not included in the cost modelling because clinical trial data showed that rivaroxaban is non-inferior to traditional therapy, so outcomes were assumed to be equivalent. Furthermore, assumptions were made and several different sources were used in order to estimate various fixed and variable costs to complete the cost analyses. The cost analyses are specific to the practice at two hospitals in $\mathrm{BC}$ and other hospitals across Canada that have similar ED programs in place; they may not apply to outpatient anticoagulation clinics, which have different workflow and cost models. ${ }^{16}$ In addition, costs are specific to the practice setting, city, and province of this study; although comparable to other jurisdictions, costs will obviously differ between settings.

\section{CONCLUSIONS}

In summary, rivaroxaban would realize a cost avoidance of $\$ 1,488.05$ per VTE event versus traditional anticoagulation, with a resultant increase in costs to the patient of approximately $\$ 200$ to $\$ 350$. This analysis suggests that DOACs are a cost-effective and viable option for VTE treatment in the ED, for those patients appropriate for outpatient therapy. For those remaining on traditional anticoagulation, measures should be taken in order to minimize direct and indirect costs to the hospital and patient such as streamlining of ED visits, updating VTE treatment pathways, and/or specific anticoagulation clinics dedicated to bridging anticoagulation.

Acknowledgements: Presented at the Canadian Association of Emergency Physicians Annual General Meeting, Ottawa, Ontario, June 2014.

Special thanks to Kimberly Hilchie, UBC Pharmacy Student, for her assistance in data collection.

Competing interests: Dr. Harris has been supported by Bayer (consulting), Pfizer (consulting). No sponsorship or funding was provided for this research. 


\section{REFERENCES}

1. Franchini M, Mannucci PM. New anticoagulants for treatment of venous thromboembolism. Eur 7 Intern Med 2012;23(8):692-5.

2. Guyatt GH, Akl EA, Crowther M, et al. Executive summary: Antithrombotic Therapy and Prevention of Thrombosis, 9th ed: American College of Chest Physicians EvidenceBased Clinical Practice Guidelines. Chest 2012;141 (2 Suppl):7S-47S.

3. Pollack C. New oral anticoagulants in the ED setting: a review. Am 7 Emerg Med 2012;30(9):2046-54.

4. Fox BD, Kahn SR, Langleben D, et al. Efficacy and safety of novel oral anticoagulants for treatment of acute venous thromboembolism: direct and adjusted indirect meta-analysis of randomised controlled trials. BM7 2012;345:e7498.

5. Rudd KM, Phillips EL. New oral anticoagulants in the treatment of pulmonary embolism: efficacy, bleeding risk, and monitoring. Thrombosis 2013;2013:973710. doi:10.1155/ 2013/973710.

6. Nutescu E. Emerging options in the treatment of venous thromboembolism. Am 7 Health Syst Pharm 2004;61 (23 Suppl 7):S12-7.

7. Bauersachs R, Berkowitz SD, Brenner B, et al. Oral rivaroxaban for symptomatic venous thromboembolism. New Engl 7 Med 2010;363(26):2499-510.

8. Büller HR, Prins MH, Lensin AW, et al. Oral rivaroxaban for the treatment of symptomatic pulmonary embolism. New Engl 7 Med 2012;366(14):1287-97.

9. Sardar P, Chatterjee S, Mukherjee D. Efficacy and safety of new oral anticoagulants for extended treatment of venous thromboembolism: systematic review and meta- analyses of randomized controlled trials. Drugs 2013;73 (11):1171-82.

10. Kaji AH, Schriger D, Green S. Looking through the retrospectoscope: reducing bias in emergency medicine chart review studies. Ann Emerg Med 2014;64(3):292-8.

11. Canadian Institute for Health Information (CIHI). Health care cost drivers; 2011. Available at: http://www.cihi.ca/CIHIext-portal/pptx/internet/HOSPITAL_COST_DRIVERS_EN (accessed September 15, 2014).

12. British Columbia Ministry of Health. Laboratory Services Outpatient Payment Schedule. Laboratory, Diagnostic and Blood Services Branch; 2014. Available at: http://www2.gov. bc.ca/gov/content/health/practitioner-professional-resources/ laboratory-services/information-for-laboratory-operators/ laboratory-services-outpatient-payment-schedule (accessed September 15, 2014).

13. Guidelines and Protocols Advisory Committee. Warfarin therapy management. Victoria, BC: British Columbia Ministry of Health Services; 2010: 1-10.

14. Prins $\mathrm{MH}$, Lensing AW, Bauersachs $\mathrm{R}$, et al. Oral rivaroxaban versus standard therapy for the treatment of symptomatic venous thromboembolism: a pooled analysis of the EINSTEIN-DVT and PE randomized studies. Thromb $\mathcal{f}$ 2013;11(1):21.

15. Beyer-Westendorf J, Förster K, Pannach S, et al. Rates, management, and outcome of rivaroxaban bleeding in daily care: results from the Dresden NOAC registry. Blood 2014;124(6):955-62, doi:10.1182/blood-2014-03-563577.

16. Van Walraven C, Jennings A, Oake N, et al. Effect of study setting on anticoagulation control: a systematic review and metaregression. Chest 2006;129(5):1155-66. 